\title{
Blended Learning on Mathematical Analysis in Nomotex Digital Learning System
}

\author{
Yury I. Dimitrienko ${ }^{1}$, Michael P. Gordin ${ }^{1}$, Elena A. Gubareva ${ }^{1 *}$, and Anna E. Pichugina ${ }^{1}$ \\ ${ }^{1}$ Bauman Moscow State Technical University, 2nd Baumanskaya str., 5/1, 105005, Moscow, Russia
}

\begin{abstract}
The paper discusses the methodology and technology of teaching the discipline «Mathematical Analysis» using the new Digital Learning System Nomotex (the Nomotex DLS), developed at the Department of «Computational Mathematics and Mathematical Physics» Bauman Moscow State Technical University (BMSTU). A new conceptual model for conducting lectures and practical classes in blended learning is presented. Examples of interactive computer visualization of some mathematical concepts within the discipline «Mathematical analysis» are presented.
\end{abstract}

\section{Introduction}

The discipline «Mathematical Analysis» is a classic discipline that is taught in any technical university with different depth and breadth of study of the material. In this work, we want to present a completely new approach to the methodology and technology of teaching this discipline in the framework of blending learning, which was successfully tested at the BMSTU at the Department of Computational Mathematics and Mathematical Physics (FS11).

This approach implements the methodology and technology of teaching in the Nomotex DLS, developed at the Department of FS-11, Bauman Moscow State Technical University $[1,3,4]$. The Nomotex DLS was created on the basis of Web-technology, which allows using it in the presence of the Internet from any device that has access to it, in particular laptops, tablets and mobile phones. In this regard, the possibility of remote training of students is fully realized, without losing the quality of training.

\section{Configuration of the course «Mathematical Analysis» in the Nomotex DLS}

The academic discipline «Mathematical Analysis» is read by the Department of "Computational Mathematics and Mathematical Physics" (FS-11) of the Bauman Moscow State Technical University for bachelors studying in the direction of training 02.03.01 "Mathematics and Computer Science" in the first year for 2 semesters.

*Corresponding author: gubareva_ea@bmstu.ru 
The course of mathematical analysis is the main base for the preparation of bachelors in the direction of preparation 02.03.01 "Mathematics and Computer Science", which until 2018 was taught by the classical method. This course was significantly modernized in connection with the introduction of the innovative Digital Learning System Nomotex, developed at the Department of FS-11 of the Bauman Moscow State Technical University $[1,3,4]$. The Nomotex DLS is based on Web technology, which allows you to use it in the presence of the Internet from any device that has access to it, in particular laptops, tablets and mobile phones. Various approaches using information technology are presented in [59].

At the first lecture («0»-lection) of the course «Mathematical Analysis» the teacher introduces the students to the possibilities of the Nomotex DLS. Before the start of $\langle 0 »\rangle-$ lecture students and teachers are given a login and password by administrators, which allows them to access the Nomotex DLS.

The teacher also demonstrates the basic functionality of the system, which is necessary for the successful mastering of the discipline.

\subsection{The main subsystems for completing the mathematical analysis course at the Nomotex DLS}

All training courses are located in the subsystem "Implementation of neural network educational programs", in order to select the required course, you must select your educational program, and then find the required course by name.

The configuration of the course «Mathematical Analysis» is as follows: the lectures are built in the form of a hierarchical neural network model proposed in [2] and divided into sections, topics and quanta of knowledge (axioms, definitions, theorems, etc.). The user (teacher, student) can choose the course display mode:

-structure - the course itself is shown, then you can open the tree-like configuration of the course and look at the paragraphs, as well as quanta (the minimum unit of knowledge, which is an axiom, definition, theorem, statement, according to the knowledge representation model [2]), which are included in this paragraph In this mode, there is no division of the course into lectures;

- lectures and seminars - the configuration of lectures and seminars is shown;

- lectures - only the configuration of the lectures is shown;

-seminars-only the configuration of the seminars is shown.

All quanta of knowledge in the configuration of the course "Mathematical Analysis" are provided with hyperlinks, which make it possible to establish links between the studied disciplines (analytical geometry, algebra, etc.). This provides an excellent opportunity for students to recover the necessary information from related disciplines online, both in the classroom and in remote classes.

The subsystem «Implementation of neural network educational programs» is the main one for the course «Mathematical analysis».

However, often, students want to see only certain, specific mathematical examples or problems, this need of students is implemented in Nomotex DLS in the "Visual Mathematics» subsystem (Fig. 1).

It presents a wide range of mathematical examples and problems, structured according to the topics of the course "Mathematical Analysis". 

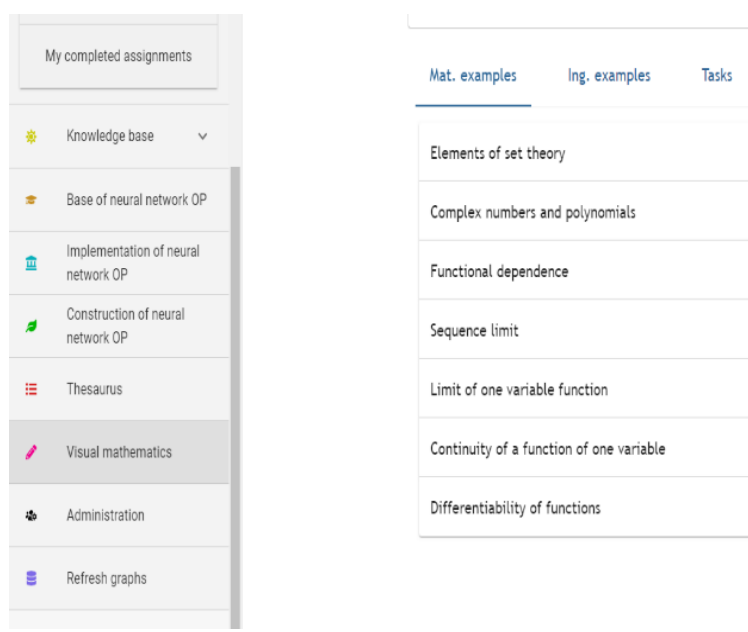

Fig. 1. Window of the «Visual mathematics» subsystem in the Nomotex DLS. Course «Mathematical analysis», Mathematical examples.

Mathematical examples are animated visualizations with varying parameters of a mathematical concept. Figure 2 shows the visualization of the mathematical concept «Complex function».

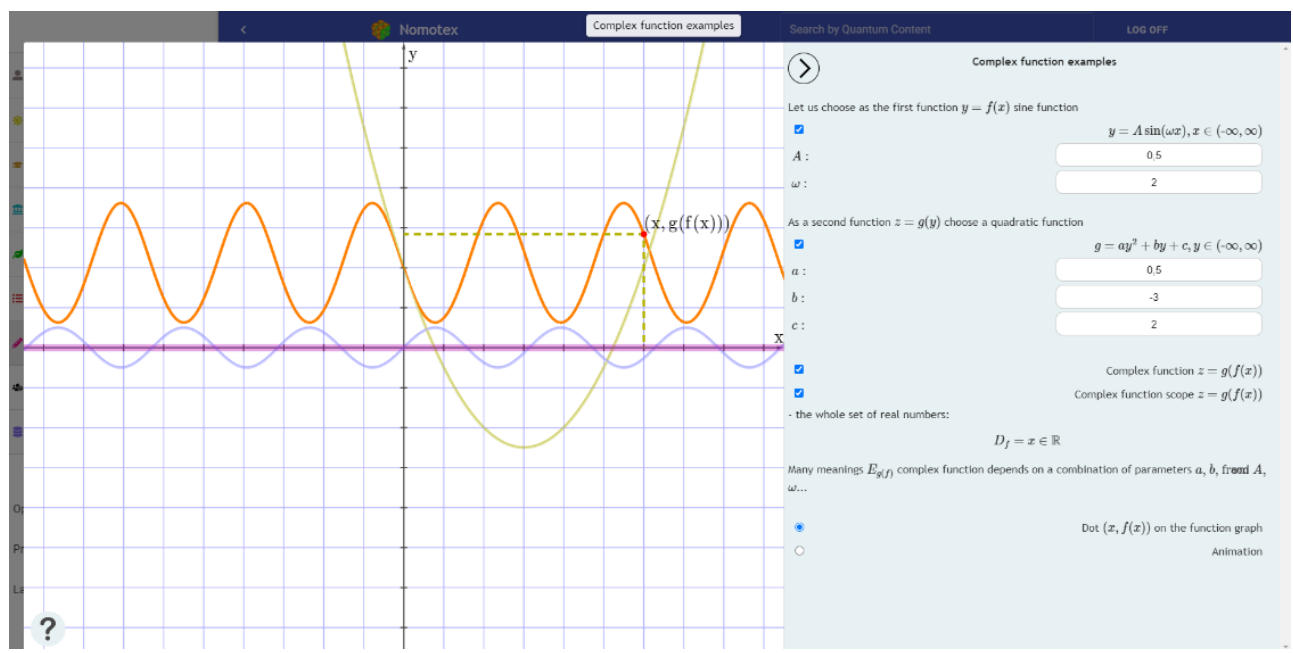

Fig. 2. Window of the subsystem «Visual mathematics» in the Nomotex DLS. Course «Mathematical analysis», Mathematical example «complex function».

The student is offered a choice of two functions, the parameters included in the equation, the student can vary, and there is also the possibility of graphical construction of two options for complex functions. Each step (parameter selection, function selection, point selection) is fully visualized.

\section{Technology of conducting classes in the discipline "Mathematical analysis"}

The course "Mathematical Analysis" consists of the following structural elements:

-Lectures; 

-Seminars;
-Control activities (Midterm controls and lecture microcontrol, Homework);
-Independent work.

\subsection{The technology of conducting lectures on the course «Mathematical analysis»}

When delivering lectures in class, the teacher uses an interactive whiteboard, working in the subsystem "Neural network educational programs", while students outline the main points of the lecture, which the teacher focuses on. The remaining unrecorded lectures, students finish writing at home. The main time when lecturing is given not to dictation of the lecture material, but to the visualization component of the lectures: specific mathematical and engineering examples illustrating a specific mathematical concept, as well as on the connection of mathematical concepts with each other.

This approach ensures the systematic assimilation of all mathematical concepts by students, as well as the connections between them, which allows them to successfully form the mathematical apparatus for further research.

For example, consider the quantum of knowledge "Equivalence of the definitions of functions according to Cauchy and according to Heine", which is in lecture 8, in the paragraph "The concept of the limit of a function"

This quantum includes three subquanta:

-Formulation of the theorem (in the form of a traffic light [2])

-Proof of the theorem;

-Mathematical example illustrating the application of the theorem.

The formulation of the theorem represents the logical structure of the theorem on the equivalence of limits according to Cauchy and Heine (Fig. 3), in addition to the formulation itself in the form of a traffic light, on the right is a circle of knowledge, a paragraph, and small dots on the circle of knowledge are quanta. Arcs connecting quanta are logical connections between quanta (mathematical concepts), which are represented in the text by hyperlinks [2].
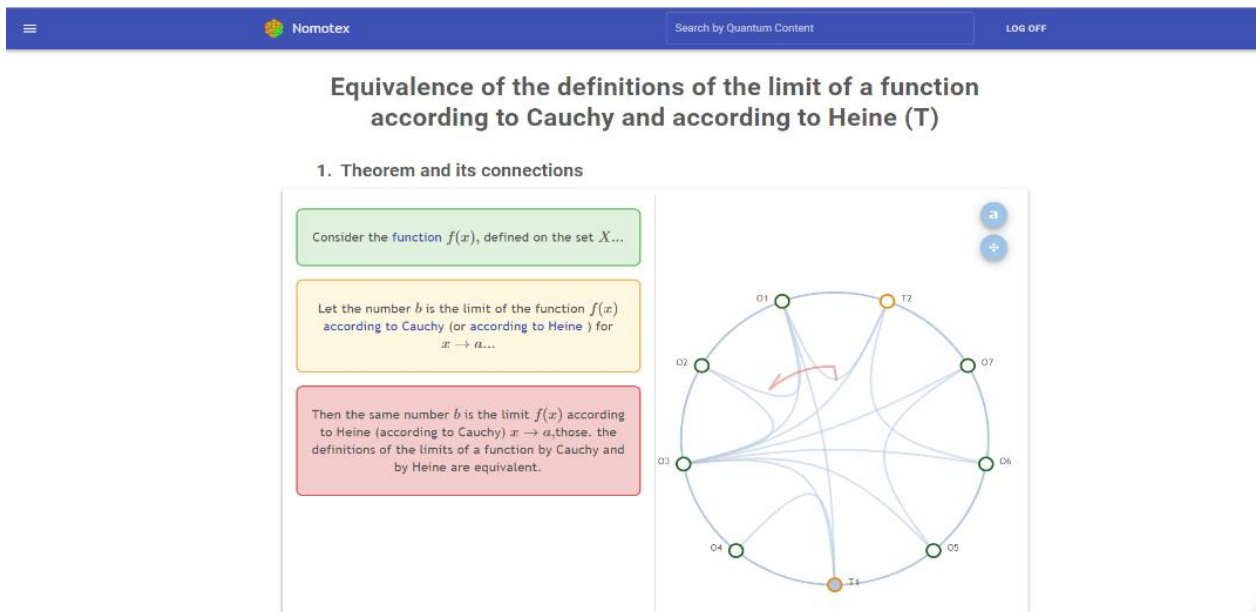

Fig. 3. Window of the «Implementation of neural network programs"» subsystem in the Nomotex DLS. Course «Mathematical analysis», paragraph «The concept of the limit of a function», lecture 8, quantum Equivalence of definitions according to Cauchy and Heine. Traffic light.

The proof of the theorem has a standard text form in this case (there are also graphic proofs with full visualization) (Fig. 4). 


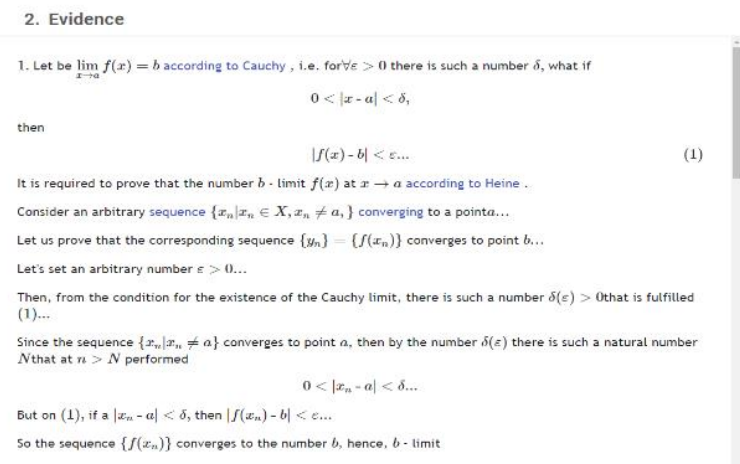

Fig. 4. Window of the «Implementation of neural network programs» subsystem in the Nomotex DLS. Course «Mathematical analysis», paragraph «The concept of the limit of a function», lecture 8, quantum Equivalence of definitions according to Cauchy and Heine. Proof of the theorem.

The mathematical example (Fig. 5) is the culmination of the entire quantum, because it is in this subquantum that the student is aware of all abstract actions with sequence and function, and it is here that a clear awareness of abstract mathematical constructions that are incredibly difficult for engineers occurs. The limit of the sequence is one of the first difficult things in the course "Mathematical analysis" to understand, this is where the concept of surroundings arises, quanta of existence and uniqueness arise that have not been encountered by the student before.

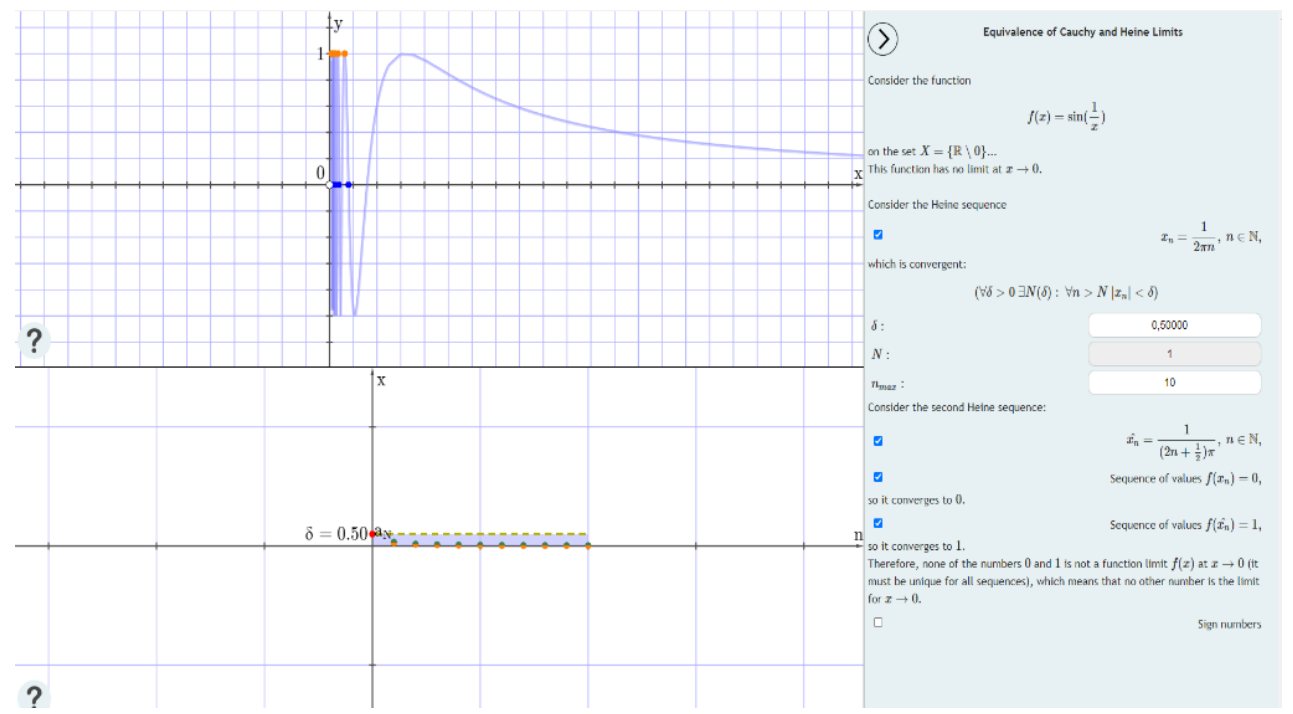

Fig. 5. Window of the «Implementation of neural network programs» subsystem in the Nomotex DLS. Course «Mathematical analysis», paragraph «The concept of the limit of a function», lecture 8, quantum Equivalence of definitions according to Cauchy and Heine. Mathematical example.

Blending learning technology for lecturing is implemented in the form of a combination of classical text (definition, formulation of theorems), textual proof, and a powerful visualization base of mathematical examples. The study of a mathematical concept does not 
occur due to memorization of the text (and when an abstract new concept occurs, it does), but due to the visualization of the image that forms this mathematical concept.

\subsection{The technology of conducting practical classes on the course "Mathematical Analysis"}

The technology for conducting practical exercises also involves the use of an interactive whiteboard. The seminars themselves are fully represented at the Nomotex DLS. The teacher demonstrates the solution to the problem (Fig. 6), and then students are invited to solve problems on their own, while there are several classes of problems:

- problems with an open solution algorithm and a known answer;

- problems with an open solution algorithm, while the answer is unknown and must be entered into the system;

- problems with a closed algorithm for solving and answering.

Most of the tasks are graphically rendered.

Students solve problems at the desk or at the interactive whiteboard. Answers can be entered on students' computers or smartphones.

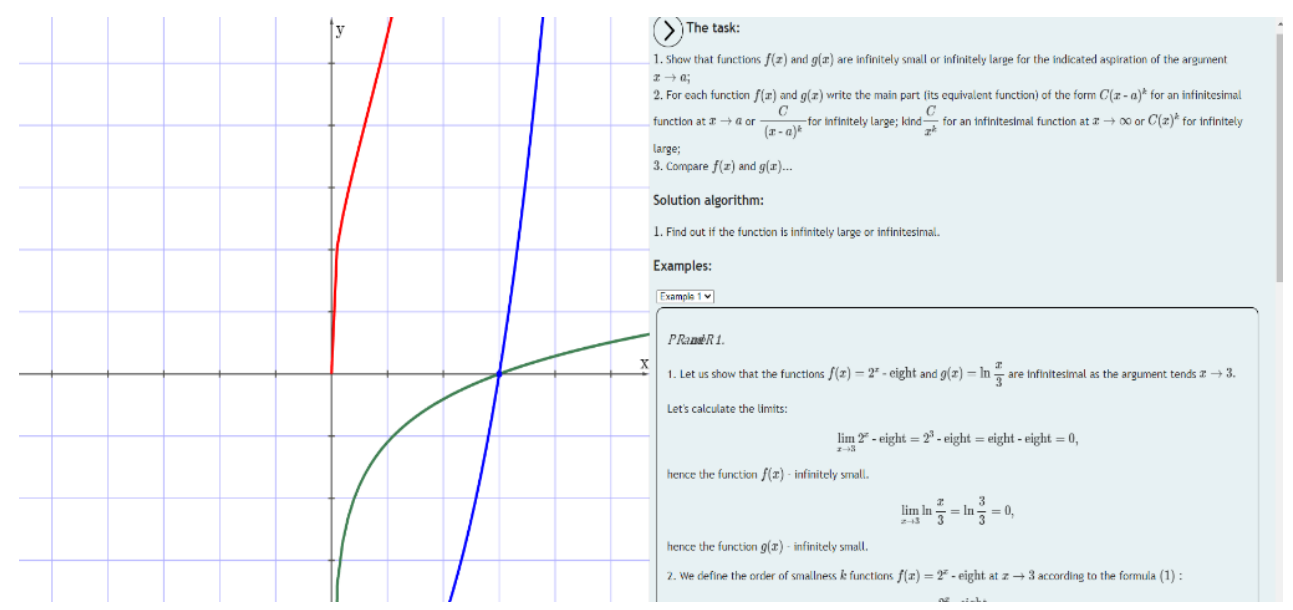

Fig. 6. Seminar problem with open solution algorithm and graphical visualization answer on the topic "Determining the order of one infinitely large function relative to another" in the Nomotex DLS.

\subsection{The technology of control events in the course "Mathematical Analysis"}

Consider the technology of conducting a control event- lecture microcontrol.

Lecture microcontrols are designed to improve the study of lecture material. Lecture microcontrols are issued before the start of each lecture. Lecture microcontrolled tasks consist of the topic of the previous lecture.

The teacher issues lecture microcontrollers from his personal account, and students use smartphones when writing and handing over microcontrollers. An example of a lecture microcontroller is shown in Fig. 7. 


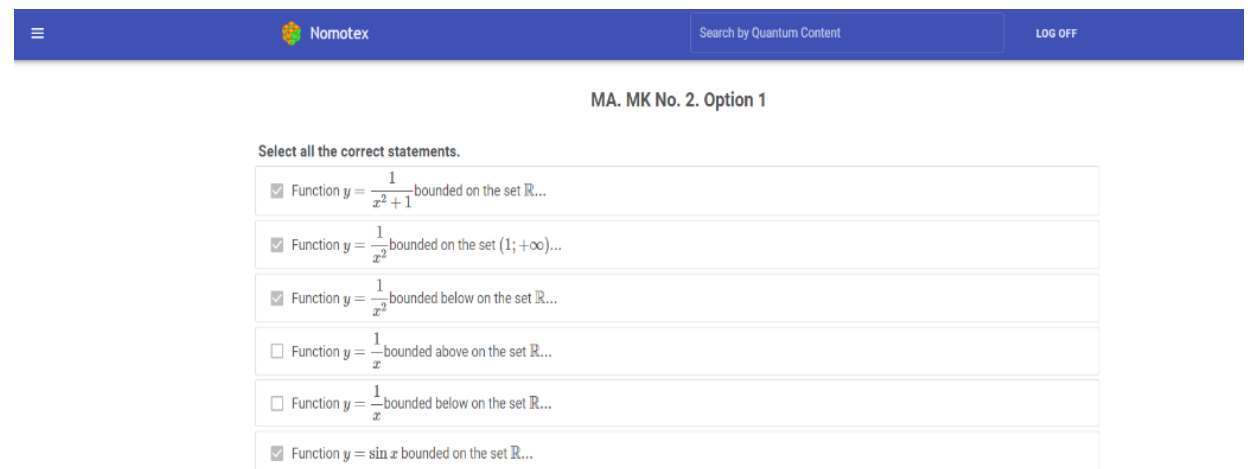

Fig. 7. Lecture microcontroller example at the Nomotex DLS. Course «Mathematical Analysis».

\section{Conclusions}

Training in the course "Mathematical Analysis" in a mixed format for students on the Nomotex DLS using the new technology was successful. Testing the student's knowledge showed an improvement in the percentage of mastering mathematical concepts of the course "Mathematical Analysis". In a survey of students, 97 percent noted that visualizing mathematical concepts makes them easier to learn and understand. The introduced lecture microcontrols improved the quality of theoretical knowledge demonstrated by students.

\section{References}

1. Yu.I. Dimitrienko, E.A. Gubareva, A new technology for the mathematical training of engineering personnel based on a neural network model of knowledge, Innovations in Education, No. 11, pp.129-140 (2017)

2. Yu.I. Dimitrienko, E.A. Gubareva, Hierarchical neural network model for mathematical knowledge and software NOMOTEX for mathematical training of engineers, IOP Journal of Physics: Conference Series, volume 1141 012010, DOI:10.1088/1742-6596/1141/1/012010 (2018)

3. Yu.I. Dimitrienko, E.A. Gubareva, T.V. Oblakova, A.A.Prozorovskiy, Primeneniye tsifrovoy obrazovatel'noy credy NOMOTEX dlya obucheniya inzhenerov po kursu «Analiticheskaya geometriya», Dnevnik nauki, № 10 (22), pp. 7-15 (2018)

4. Yu.I. Dimitrienko, E.A. Gubareva, D.A Chebakov, Konstruirovaniye elektronnykh interaktivnykh kursov v tsifrovoy obrazovatel'noy srede NOMOTEX, Dnevnik nauki, №11, http://dnevniknauki.ru/im...ubareva Chebakov.pdf (2019)

5. N.A. Serdyukova, V.I. Serdyukov, Smart System Sustainability and Smart System Management (to be published) Intelligent Systems Reference Library, 191, pp. 157172, DOI: 10.1007/978-3-030-54470-6_9 (2021)

6. E.V. Lyapuntsova, I.M. Belozerova, V.G. Borkovskaya, I.I. Drozdova, Y.S. Baranova, Organization and Management of Educational Work in Universities in the Light of National Strategic Guidelines for the Development of Education, IOP Conference Series: Earth and Environmental Science, 459 (6), № 062031, DOI: $10.1088 / 1755-1315 / 459 / 6 / 062031$ (2020)

7. A. Yermakov, I. Stroganov, A system for modelling and visualizing processor state during code execution, eLearning and Software for Education Conference, pp. 438443. DOI: $10.12753 / 2066-026 X-19-058$ (2019) 
8. V.A. Shakhnov, A.A. Glushko, E.V. Rezchikova, L.A. Zinchenko, V.V. Terekhov, V.V. Makarchuk, TCAD and Cognitive Visualization in Electronic Engineering Education : BMSTU Case Study, 2020 5th International Conference on Information Technologies in Engineering Education, Inforino 2020 - Proceedings, № 9111802, DOI: 10.1109/Inforino48376.2020.9111802 (2020)

9. T.Yu. Tsibizova, V.M. Postnikov, S.B. Spiridonov, Analysis of the impact of technology lectures-visualizations on the results of control measures in various academic disciplines, Perspektivy Nauki i Obrazovania, 33 (3), pp. 358-363(2018) 